\title{
Baseline Body Composition in Prepubertal Short Stature Children with Severe and Moderate Growth Hormone Deficiency
}

\author{
Pawel Matusik, ${ }^{1}$ Marta Klesiewicz, ${ }^{2}$ Karolina Klos, ${ }^{2}$ Martyna Stasiulewicz, \\ Aleksandra Barylak, ${ }^{2}$ Patrycja Nazarkiewicz, ${ }^{2}$ and Ewa Malecka-Tendera ${ }^{1}$ \\ ${ }^{1}$ School of Medicine in Katowice, Department of Pediatrics and Pediatric Endocrinology, Medical University of Silesia, Katowice, Poland \\ ${ }^{2}$ Scientific Society of Medical Students, Medical University of Silesia, Katowice, Poland
}

Correspondence should be addressed to Pawel Matusik; endocrin@wp.pl

Received 30 March 2016; Accepted 14 August 2016

Academic Editor: Donatella Capalbo

Copyright (c) 2016 Pawel Matusik et al. This is an open access article distributed under the Creative Commons Attribution License, which permits unrestricted use, distribution, and reproduction in any medium, provided the original work is properly cited.

Objective. To compare body composition parameters in short children with severe versus moderate and no growth hormone deficiency (GHD). Design and Method. 61 children (40 boys) were studied. Height SDS, BMI Z-score, waist/height ratio (W/HtR), and body composition parameters (BIA) as fat tissue (FAT\%), fat-free mass (FFM\%), predicted muscle mass (PMM\%), and total body water (TBW\%) were evaluated. GH secretion in the overnight profile and two stimulation tests and insulin-like growth factor 1 (IGF-1) level were measured. Results. Overall, in $16(26 \%)$ moderate $(7.0>$ peak GH $<10 \mathrm{ng} / \mathrm{mL})$ and in $11(18 \%)$ severe $(\mathrm{GH} \leq$ $7.0 \mathrm{ng} / \mathrm{mL}$ ) GHD was diagnosed. In children with sGHD BMI $Z$-score, W/HtR and FAT\% were significantly higher, while FFM\%, PMM\%, and TBW\% were significantly lower versus $\mathrm{MGHD}$ and versus noGHD subgroups. No significant differences between mGHD and noGHD were found. There were no differences in height SDS and IGF-1 SDS between evaluated subgroups. Night GH peak level correlated significantly with FAT\%, FFM\%, PMM\%, and TBW\%, $(p<0.05)$ in the entire group. Conclusions. Only sGHD is associated with significant impairment of body composition. Body composition analysis may be a useful tool in distinguishing between its severe and moderate form of GHD.

\section{Introduction}

The prevalence of growth hormone deficiency (GHD) is estimated on 1:4000 to $1: 20000$ of children which places this pathology in the group of rare diseases [1]. However, the number of children referred to Pediatric Endocrinology Clinics for short stature evaluation is much higher. Moreover, in many of them GHD based on the results of GH stimulation tests is diagnosed and they are treated for several years with daily injections of recombinant $\mathrm{GH}(\mathrm{rGH})$. Although in children with mid-line defects or in severe idiopathic GHD deficiency the diagnosis is clear and substitution of the missing hormone is essential for linear growth, glucose homeostasis, and development of normal body composition [2-4], in many short stature patients with mild GH deficiency the diagnosis remains equivocal. In this group the results of the prolonged, expensive, and invasive treatment with $\mathrm{rGH}$ are often not satisfactory and the individual response varies widely [5-7].
The diagnosis of GHD is based on auxological parameters and on the results of two stimulation tests which are supposed to examine the pituitary GH reserve. Various substances are being used for laboratory testing (e.g., insulin, arginine, glucagon, and clonidine) as well as overnight GH secretion, none of them being the ideal one. The tests are poorly reproducible and children with GHD quite often have a normal response in later life [8-11]. Cut-off value of peak GH secretion is also more or less arbitrary. In most pediatric endocrinology centers the diagnosis of GHD is made on the basis of peak GH concentration $\leq 10 \mathrm{ng} / \mathrm{mL}$, as published in the GH Research Society guidelines in 2000 [12]. This cutoff value is being questioned by several authors who suggest that this concentration is too high and should be lowered to 7 or $8 \mathrm{ng} / \mathrm{mL}[9,13,14]$. However traditionally a peak GH between 7 and $10 \mathrm{ng} / \mathrm{mL}$ is considered indicative of moderate GHD (mGHD) and children with this diagnosis are treated in the same manner as these with severe GHD (sGHD) $[6,7]$. Moreover, in many mGHD patients low insulin-like growth 
factor (IGF-1) concentration is found, which strengthens the hypothesis that such children have clinical characteristics intermediate between sGHD and no growth hormone deficient (noGHD) short children [6].

Severe GHD induces abnormalities in body composition such as increased fat mass and reduced lean body mass [1517]. Khadilkar et al. [18] demonstrated that one year of $\mathrm{rGH}$ therapy not only significantly reduced the fat mass (by 15\%) but also had a beneficial effect on the cardiovascular risk reducing carotid intima media thickness (cIMT) in children with GHD. Ciresi et al. [19] showed a beneficial effect of rGH administration on metabolic parameters such as leptin level and insulin resistance (HOMA-IR) in GH deficient children. The link between rGH therapy and body composition improvement was particularly observed in children with Prader-Willi syndrome. $\mathrm{rGH}$ administration in these patients resulted in fat mass reduction and gain in lean body mass and was maintained over the years [20].

Body composition parameters have not been extensively studied in children with impaired GD secretion who do not fulfil the stringent criteria of sGHD and in whom mGHD is diagnosed. The aim of our study was to compare body composition parameters in short children with sGHD, mGHD, and noGHD. We hypothesized that children with mGHD will have characteristics intermediate between two other groups.

\section{Design and Methods}

2.1. Study Population. Study Group (SG) comprised 61 prepubertal short children ( 40 boys and 21 girls) at the mean age of $10.7 \pm 2.6$ years. They were consecutively recruited for the study from the patients referred to our Department between September 2013 and March 2014. Exclusion criteria comprised chromosomal aberrations, dysmorphic syndromes, bone dysplasia, children born small for gestational age or with intrauterine growth retardation, and patients with chronic diseases, acquired GHD, including posttraumatic or postneoplastic deficiencies.

2.2. GHD Diagnosis. Short stature was defined as the height below 2 standard deviation scores (SDS) from the population mean, referred to the national growth charts [21]. Peak GH concentration below $10 \mathrm{ng} / \mathrm{mL}$ in the night profile and two stimulation tests (after clonidine and insulin administration) were considered diagnostic for GHD. Stimulation test methodology was as follows: oral administration of clonidine at the dose of $0.15 \mathrm{mg} / \mathrm{m}^{2}$ body surface (Iporel, Polfa) and intravenous administration of insulin in the dose of $0.1 \mathrm{U} / \mathrm{kg}$ (Actrapid, NovoNordisk) resulting in hypoglycaemic state (serum glucose concentration below $40 \mathrm{mg} / \mathrm{dL}$ ). Blood samples for $\mathrm{GH}$ estimation were collected every 30 minutes (from 0 to $120 \mathrm{~min}$ ) for both tests, clonidine or insulin. $\mathrm{GH}$ concentrations were measured by a two-site chemiluminescent enzyme immunometric assay (hGH IMMULITE, DPC). Children with GHD were then categorized according to the maximal $\mathrm{GH}$ level into moderate and severe GHD ( $\max \mathrm{GH} \geq 7.0 \mathrm{ng} / \mathrm{mL}$ and $<7.0 \mathrm{ng} / \mathrm{mL}$, resp.). Additionally, the concentration of IGF-1 was measured by solid-phase enzyme-labelled chemiluminescent immunometric assays (IMMULITE, DPC) in all children and was analyzed as a number of standard deviation score (SDS) from the mean. Bone age (BA) was assessed using the Greulich and Pyle method [22]. Based on the normal picture of the magnetic resonance imagining (MRI) idiopathic form of GHD was diagnosed in both mGHD and sGHD subgroups.

2.3. Ethical Considerations. The study was approved by the Ethics Committee of Medical University of Silesia. All parents or caregivers gave their informed consent. Patient rights were also respected according to the Declaration of Helsinki with its subsequent modifications.

2.4. Anthropometric Measurements. Standing height was measured by a wall-mounted Harpenden Stadiometer to the nearest $0.1 \mathrm{~cm}$ and weight (in patients in their underwear) by electronic scale with readings accurate to $0.1 \mathrm{~kg}$. Height standard deviation score (HSDS) was calculated for all studied children referred to the national growth charts [21]. Midparental height (MPH) SDS and $\Delta$ height SDS (HSDS MPH SDS) were also assessed. Body mass index (BMI) was calculated, using the standard formula (kilograms per meter squared). BMI $Z$-scores were derived using WHO AnthroPlus, version 1.0.4 (based on World Health Organization growth references) [23]. Waist circumference was measured midway between the lower rib margin and the iliac crest in the standing position and waist/height ratio $(\mathrm{W} / \mathrm{HtR})$ was calculated.

2.5. Body Composition Analysis. Body composition parameters: fat mass (FAT), fat-free mass (FFM), predicted muscle mass (PMM), and total body water (TBW) were assessed (as percentage of body weight [\%]) based on bioelectrical impedance analysis (BIA) using segmental body composition analyzer (MC-980 MA Tanita Europe BV, Hoofddorp, the Netherlands).

2.6. Statistical Analysis. Normal distribution of all variables was confirmed by the Kolmogorow-Smirnov test. Comparative analysis of the groups for variables of normal distribution was carried out using one-way ANOVA and results were reported as least squares mean $\pm 95 \%$ confidence interval (CI). Further post hoc analysis was based on the Bonferroni test. Correlations between variables within studied group were based on linear Pearson's correlation coefficient. All statistical analysis was made by the Statistica ${ }^{\mathrm{TM}} 10 \mathrm{PL}$ software and $p<0.05$ was considered significant.

\section{Results}

In 34 (66\%) of children GHD was excluded (noGHD group). Based on the peak GH concentration 27 children with GHD were subdivided into two groups, moderate (mGHD, $n=16$ ) and severe growth hormone deficient ( $\mathrm{GHHD}, n=11$ ).

None of the three subgroups differed significantly by means of chronological age, BA and gender distribution (Table 1). Post hoc analysis revealed that patient with sGHD differed significantly from both $\mathrm{mGHD}$ and noGHD, having 


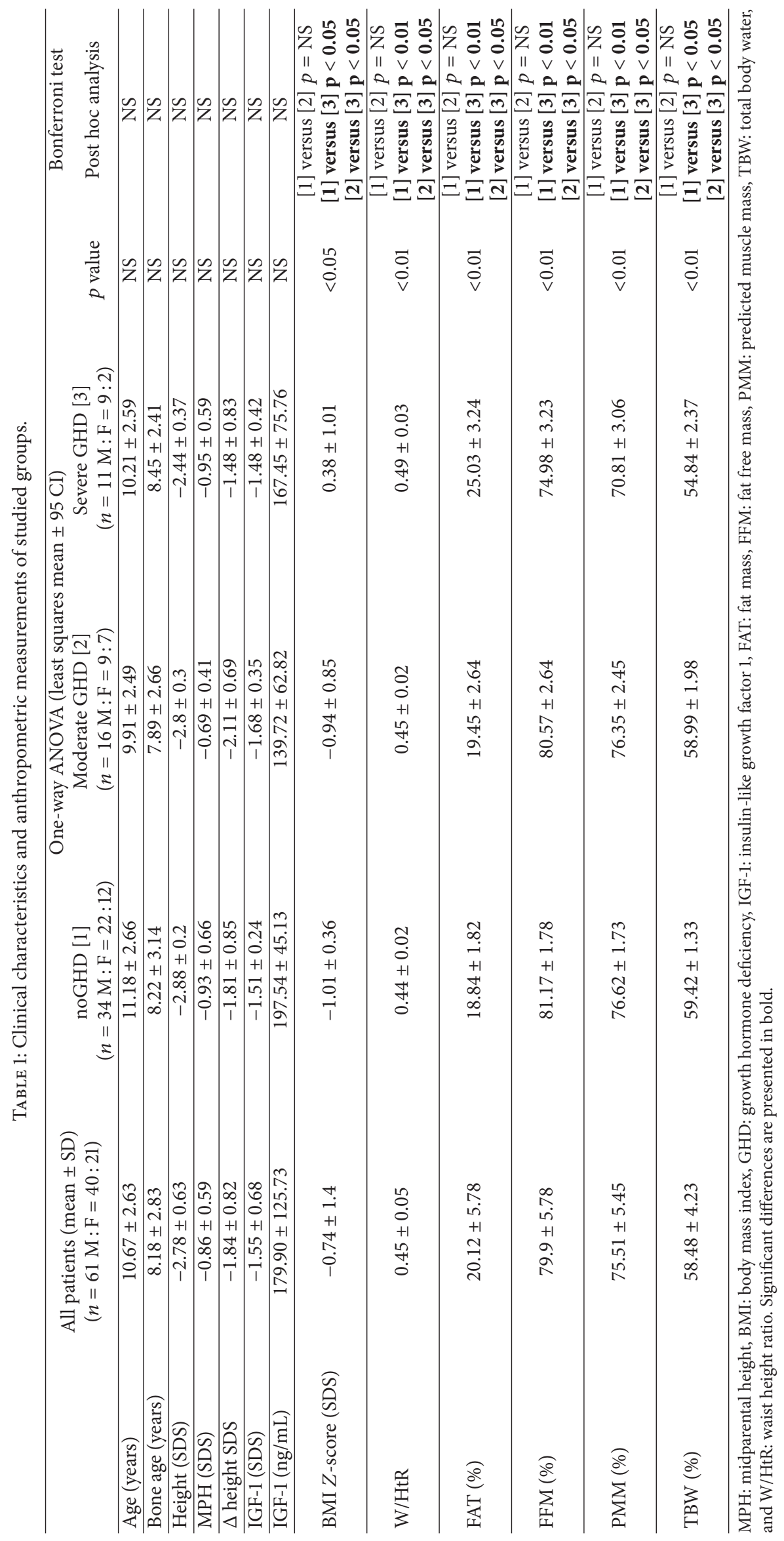


TABle 2: Significant Pearson's correlations between peak GH level in the night profile and body composition parameters in the study group.

\begin{tabular}{lcc}
\hline \multicolumn{3}{c}{$\begin{array}{c}\text { All patients }(n=61) \\
\text { Peak GH level in the night profile } \\
\text { Pearson's correlation }\end{array}$} \\
\hline FAT (\%) & $r=-0.311$ & Significance \\
FFM (\%) & $r=0.314$ & $p<0.05$ \\
PMM (\%) & $r=0.313$ & $p<0.05$ \\
TBW (\%) & $r=0.313$ & $p<0.05$ \\
\hline
\end{tabular}

FAT: fat mass, FFM: fat free mass, GH: growth hormone, PMM: predicted muscle mass, and TBW: total body water.

higher BMI $Z$-score, $\mathrm{W} / \mathrm{HtR}$, and fat tissue (FAT\%) $(p<0.05$; $p<0.01 ; p<0.01$, resp.), while other body composition parameters such as FFM\%, PMM\%, and TBW\% were significantly lower $(p<0.01)$ in the sGHD group. All measured anthropometrical parameters in children with mGHD were not significantly different from children with normal GH. No statistically significant differences in height SDS, $\Delta$ height SDS, and IGF-1 SDS were found between all three evaluated subgroups (Table 1). Moreover, children with IGF-1 SDS $<-2$ $(n=20)$ did not differ significantly in anthropometrical and body composition parameters from those with IGF-1 SDS $\geq$ $-2(n=41)$. However, peak GH level in the night profile correlated significantly with body composition parameters in the whole studied population $(r=-0.311$ for FAT\%, $r=0.314$ for FFM\%, $r=0.313$ for PMM\%, and $r=0.313$ for TBW\%, $p<0.05)$ (Table 2).

\section{Discussion}

In our study we evaluated the usefulness of baseline body composition characteristics as the potential tool for confirming the diagnosis of severe or moderate GHD in short statured children. Similarly to other authors, we found an impairment of body composition in sGHD children who experienced increased fat mass and reduced lean body mass [15-17]. Children with sGHD also had significantly higher BMI $Z$-score and W/HtR. Moreover, children with sGHD have similar BA delay and no statistically different IGF-1 SDS level from those with $\mathrm{mGHD}$ and noGHD. Therefore in our study body composition parameters were the only ones differentiating children with sGHD from noGHDt and mGHD patients.

On the other hand we did not find any statistically significant differences neither in body composition parameters nor in BMI $Z$-score and W/HtR between $\mathrm{mGHD}$ and noGHD children. Therefore the study results did not show that children with mGHD had body composition impairment and did not support the hypothesis that children with GH level between 7 and $10 \mathrm{ng} / \mathrm{mL}$ have body composition characteristics intermediate between sGHD and noGHD patients.

The diagnosis of mGHD was questioned by several authors $[9,13]$. Many of them believe that cut-off level of GH secretion in stimulation tests should be decreased to $7 \mathrm{ng} / \mathrm{mL}$ $[9,10,13,14,24]$. Wagner et al. [13] established recently a new cut-off limit of $7.09 \mathrm{ng} / \mathrm{mL}$ which was based on clinical evidence. These new cut-off limits are recommended by Murray et al. [24] in their very recent critical review on diagnosis and management of GHD in children. The need for lowering of peak GH level was also recently confirmed by Guzzetti et al. [14]. They found that the optimal GH cut-off level varies from $5.1 \mathrm{ng} / \mathrm{mL}$ (for insulin tolerance test) to $6.8 \mathrm{ng} / \mathrm{mL}$ (for clonidine). Some studies recommend sex-steroid priming before performing GH stimulation tests in prepubertal short children to confirm the diagnosis of GH deficiency [9]. However in the study by Nwosu et al. [25] hypothesis of mGHD was not supported event in group of children receiving ethinyl estradiol or testosterone enanthate priming for 5-10 days before testing. In one of our studies final height of children with mGHD treated with rGH was not significantly different from untreated peers with idiopathic short stature matched for basal age, height, and BA delay. All of them had normal GH secretion in stimulation tests repeated after cessation of therapy [8].

Results of several studies showed that majority of adolescents having received rGH treatment during childhood for GHD have normal GH secretion at retesting after growth completion [8-11]. However according to Tauber et al. [26] about $15 \%$ of them continue to have mGHD and exhibit changes in body composition after therapy cessation similar to those seen in children with sGHD, although less marked. Discontinuation of lean body mass accrual was described by Carroll et al. [27] in patients who did not continue rGH therapy after attainment of final height, but all the subjects studied had organic GHD or sGHD. Beneficial effects of rGH therapy on body fat decrease in children born small for gestational age were reported by Willemsen et al. [28] but no such effects were found by Högler et al. [29] in children with idiopathic short stature. In the available literature we did not find data comparing body composition differences in children with moderate and severe GHD treated with rGH.

In our study, significant correlations between body composition parameters and peak $\mathrm{GH}$ in the night profile were found. Perotti et al. [30] demonstrated that peak GH in the stimulation test (GHRH-arginine) was strongly influenced by body composition. Fat mass index alone was responsible for $34.5 \%$ of the variability in peak $\mathrm{GH}$.

Significant correlation between baseline body composition assessed by BIA method and growth response to $\mathrm{rGH}$ therapy was found by Esen et al. [15] in children with GHD. Good responders had lower percentage of FFM and TBW compared to poor responders. Increased BMI $Z$-score and higher WHtR were predictors of more pronounced growth response in prepubertal subjects. The authors concluded that baseline body composition data can be used for prediction of growth response to $\mathrm{rGH}$ treatment.

Our study has two major limitations. One is the relatively small number of patients. The other is the method used for estimation of body composition by the BIA. It is not considered a gold stand technique as it may be influenced by many factors [31]. However BIA is relatively simple and noninvasive and feasible in clinical setting. Moreover, use of the dual-energy X-ray absorptiometry (DXA), which is a gold standard for the body composition analysis, is limited 
in children by radiation exposure, costs, and low availability. The process of BIA validation resulted in the development of standards and centile charts for healthy children [32]. Good correlation was found between BIA and dual-energy $\mathrm{X}$-ray absorptiometry in the study of de Lorenzo et al. [33], Loveday et al. [34], and Kehoe et al. [35]. Moreover, our recent study confirmed its utility in children and adolescents with idiopathic scoliosis [36].

The results of our study confirm previous findings that severe growth hormone deficiency is associated with an increase in fat tissue, decrease in fat-free mass, predicted muscle mass, and total body water. In contrast our results indicate that $\mathrm{mGHD}$ has no significant influence on body composition in the short statured children. Therefore, body composition assessment based on BIA seems to be a useful tool in diagnosing $\mathrm{GH}$ deficiency in children as well as in distinguishing its severe and moderate form. However the data need to be confirmed in a prospective study based on more accurate body composition assessment methods (e.g., DXA) and on a larger group of patients.

\section{Competing Interests}

The authors declare that there is no conflict of interests regarding the publication of this paper.

\section{Acknowledgments}

The study was financially supported by the Medical University of Silesia Grant (no. 1-138/N/4/0), founded by Polish Ministry of Science. The authors thank all the children who participated in this study and their parents.

\section{References}

[1] J. K. Wales, J. M. Wit, and A. D. Rogol, Pediatrics Endocrinology and Growth, Saunders, London, UK, 2003.

[2] C. Meazza, H. H. Elsedfy, S. Pagani, E. Bozzola, M. El Kholy, and M. Bozzola, "Metabolic parameters and adipokine profile in growth hormone deficient (GHD) children before and after 12-month GH treatment," Hormone and Metabolic Research, vol. 46, no. 3, pp. 219-223, 2014.

[3] Z. Aycan and V. N. Baş, "Prader-Willi syndrome and growth hormone defciency," Journal of Clinical Research in Pediatric Endocrinology, vol. 6, no. 2, pp. 62-67, 2014.

[4] M. A. Kalina, E. Skala-Zamorowska, B. Kalina-Faska, E. Malecka-Tendera, and M. Mandera, "Practical approach to childhood craniopharyngioma: a role of an endocrinologist and a general paediatrician," Child's Nervous System, vol. 25, no. 9, pp. 1053-1060, 2009.

[5] J. Van den Broeck, N. Arends, and A. Hokken-Koelega, "Growth response to recombinant human growth hormone $(\mathrm{GH})$ in children with idiopathic growth retardation by level of maximum GH peak during GH stimulation tests," Hormone Research, vol. 53 , no. 6, pp. 267-273, 2000.

[6] P. Bang, S. Faisal Ahmed, J. Argente et al., "Identification and management of poor response to growth-promoting therapy in children with short stature," Clinical Endocrinology, vol. 77, no. 2, pp. 169-181, 2012.
[7] M. O. Savage and P. Bang, "The variability of responses to growth hormone therapy in children with short stature," Indian Journal of Endocrinology and Metabolism, vol. 16, supplement 2, pp. 178-184, 2012.

[8] B. Krukowska-Andrzejczyk, M. Kalina, B. Kalina-Faska, and E. Malecka-Tendera, "Effects of treatment with recombinant growth hormone in children with transient partial growth hormone deficiency-preliminary report," Pediatric Endocrinology, vol. 12, no. 1, pp. 29-36, 2013.

[9] G. Saggese, M. B. Ranke, P. Saenger et al., "Diagnosis and treatment of growth hormone deficiency in children and adolescents: towards a consensus," Hormone Research, vol. 50, no. 6, pp. 320-340, 1998.

[10] M. Thomas, G. Massa, M. Maes et al., "Growth hormone (GH) secretion in patients with childhood-onset GH deficiency: retesting after one year of therapy and at final height," Hormone Research, vol. 59, no. 1, pp. 7-15, 2003.

[11] J. Smyczyńska, R. Stawerska, A. Lewiński, and M. Hilczer, "Incidence and predictors of persistent growth hormone deficiency (GHD) in patients with isolated, childhood-onset GHD," Endokrynologia Polska, vol. 65, no. 5, pp. 334-341, 2014.

[12] Growth Hormone Research Society, "Consensus guidelines for the diagnosis and treatment of growth hormone (GH) deficiency in childhood and adolescence: summary statement of the GH Research Society. GH Research Society," The Journal of Clinical Endocrinology \& Metabolism, vol. 85, no. 11, pp. 39903993, 2000.

[13] I. V. Wagner, C. Paetzold, R. Gausche et al., "Clinical evidencebased cutoff limits for GH stimulation tests in children with a backup of results with reference to mass spectrometry," European Journal of Endocrinology, vol. 171, no. 3, pp. 389-397, 2014.

[14] C. Guzzetti, A. Ibba, S. Pilia et al., "Cut-off limits of the peak GH response to stimulation tests for the diagnosis of GH deficiency in children and adolescents: study in patients with organic GHD," European Journal of Endocrinology, vol. 175, no. 1, pp. 4147, 2016.

[15] I. Esen, F. Demirel, D. Tepe, O. Kara, and N. Koc, "The association between growth response to growth hormone and baseline body composition of children with growth hormone deficiency," Growth Hormone \& IGF Research, vol. 23, no. 5, pp. 196-199, 2013.

[16] Y. Rakover, A. Silbergeld, I. Lavi, R. Masalha, and I. B. Shlomo, "Can exaggerated response to a GH provacative test identify patients with partial GH insensitivity syndrome?" European Journal of Endocrinology, vol. 146, no. 3, pp. 319-323, 2002.

[17] A. Mukherjee, R. D. Murray, and S. M. Shalet, "Impact of growth hormone status on body composition and the skeleton," Hormone Research, vol. 62, supplement 3, pp. 35-41, 2004.

[18] V. Khadilkar, V. Ekbote, N. Kajale, A. Khadilkar, S. Chiplonkar, and A. Kinare, "Effect of one-year growth hormone therapy on body composition and cardio-metabolic risk in Indian children with growth hormone deficiency," Endocrine Research, vol. 39, no. 2, pp. 73-78, 2014.

[19] A. Ciresi, M. C. Amato, A. Criscimanna et al., "Metabolic parameters and adipokine profile during $\mathrm{GH}$ replacement therapy in children with GH deficiency," European Journal of Endocrinology, vol. 156, no. 3, pp. 353-360, 2007.

[20] G. Grugni, A. Sartorio, and A. Crino, "Growth hormone therapy for Prader-Willi syndrome: challenges and solutions," Therapeutics and Clinical Risk Management, vol. 12, pp. 873-881, 2016. 
[21] J. Palczewska and Z. Niedźwiecka, "Wskazniki rozwoju somatycznego dzieci i mlodziezy warszawskiej," Medycyna Wieku Rozwojowego, vol. 2, supplement 1, pp. 55-114, 2001.

[22] W. W. Greulich and S. I. Pyle, Radiographic Atlas of Skeletal Development of the Hand and Wrists, Stanford University Press, Palo Alto, Calif, USA, 1959.

[23] M. de Onis, A. W. Onyango, E. Borghi, A. Siyam, C. Nishida, and J. Siekmann, "Development of a WHO growth reference for school-aged children and adolescents," Bulletin of the World Health Organization, vol. 85, no. 9, pp. 660-667, 2007.

[24] P. G. Murray, M. T. Dattani, and P. E. Clayton, "Controversies in the diagnosis and management of growth hormone deficiency in childhood and adolescence," Archives of Disease in Childhood, vol. 101, no. 1, pp. 96-100, 2016.

[25] B. U. Nwosu, M. Coco, J. Jones, K. M. Barnes, J. A. Yanovski, and J. Baron, "Short stature with normal growth hormone stimulation testing: lack of evidence for partial growth hormone deficiency or insensitivity," Hormone Research, vol. 62, no. 2, pp. 97-102, 2004.

[26] M. Tauber, B. Jouret, A. Cartault et al., "Adolescents with Partial Growth Hormone (GH) deficiency develop alterations of body composition after GH discontinuation and require follow-up," Journal of Clinical Endocrinology \& Metabolism, vol. 88, no. 11, pp. 5101-5106, 2003.

[27] P. V. Carroll, W. M. Drake, K. T. Maher et al., "Comparison of continuation or cessation of growth hormone (GH) therapy on body composition and metabolic status in adolescents with severe GH deficiency at completion of linear growth," The Journal of Clinical Endocrinology \& Metabolism, vol. 89, no. 8, pp. 3890-3895, 2004.

[28] R. H. Willemsen, N. J. T. Arends, W. M. Bakker-van Waarde et al., "Long-term effects of growth hormone $(\mathrm{GH})$ treatment on body composition and bone mineral density in short children born small-for-gestational-age: six-year follow-up of a randomized controlled GH trial," Clinical Endocrinology, vol. 67, no. 4, pp. 485-492, 2007.

[29] W. Högler, J. Briody, B. Moore, W. L. Pei, and C. T. Cowell, "Effect of growth hormone therapy and puberty on bone and body composition in children with idiopathic short stature and growth hormone deficiency," Bone, vol. 37, no. 5, pp. 642-650, 2005.

[30] M. Perotti, S. Perra, A. Saluzzi, G. Grassi, and A. I. Pincelli, "Body fat mass is a strong and negative predictor of peak stimulated growth hormone and bone mineral density in healthy adolescents during transition period," Hormone and Metabolic Research, vol. 45, no. 10, pp. 748-753, 2013.

[31] S. Y. Lee and D. Gallagher, "Assessment methods in human body composition," Current Opinion in Clinical Nutrition and Metabolic Care, vol. 11, no. 5, pp. 566-572, 2008.

[32] H. D. McCarthy, T. J. Cole, T. Fry, S. A. Jebb, and A. M. Prentice, "Body fat reference curves for children," International Journal of Obesity, vol. 30, no. 4, pp. 598-602, 2006.

[33] A. de Lorenzo, S. P. Sorge, L. Iacopino, A. Andreoli, P. Petrone De Luca, and G. F. Sasso, "Fat-free mass by bioelectrical impedance Vs dual-energy X-ray absorptiometry (DXA)," Applied Radiation and Isotopes, vol. 49, no. 5-6, pp. 739-741, 1998.

[34] S. J. Loveday, J. M. D. Thompson, and E. A. Mitchell, "Bioelectrical impedance for measuring percentage body fat in young persons with Down syndrome: validation with dual-energy absorptiometry," Acta Paediatrica, vol. 101, no. 11, pp. e491-e495, 2012.
[35] S. H. Kehoe, G. V. Krishnaveni, H. G. Lubree et al., "Prediction of body-fat percentage from skinfold and bio-impedance measurements in Indian school children," European Journal of Clinical Nutrition, vol. 65, no. 12, pp. 1263-1270, 2011.

[36] E. Matusik, J. Durmala, and P. Matusik, "Association of body composition with curve severity in children and adolescents with idiopathic scoliosis (IS)," Nutrients, vol. 8, no. 2, article 71, 2016. 


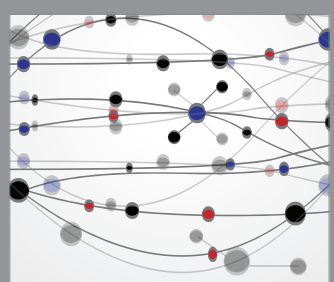

The Scientific World Journal
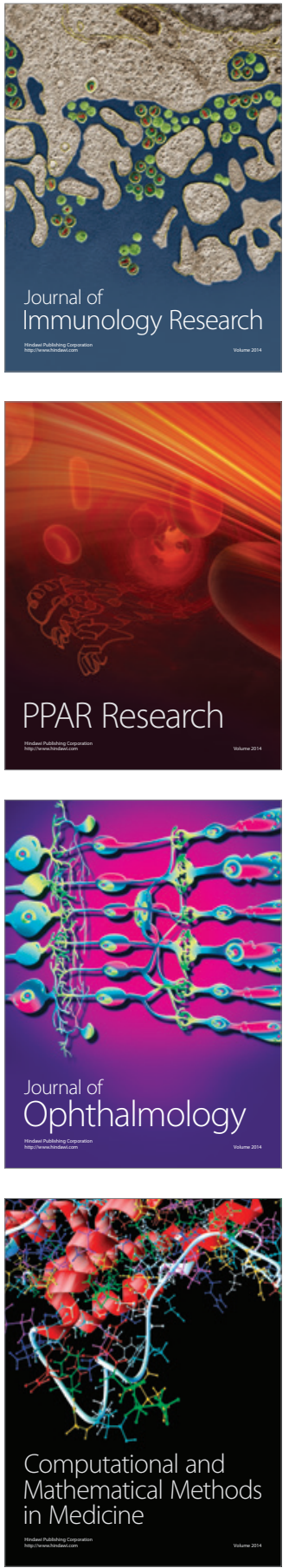

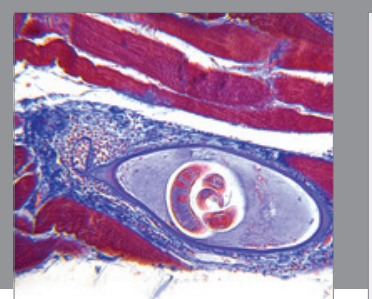

Gastroenterology Research and Practice

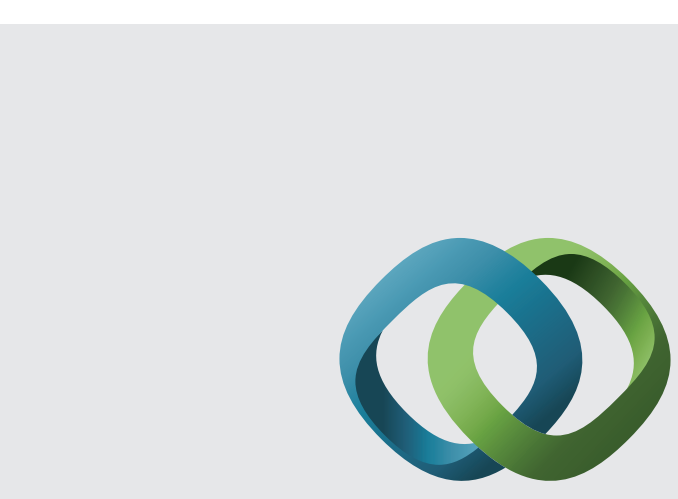

\section{Hindawi}

Submit your manuscripts at

http://www.hindawi.com
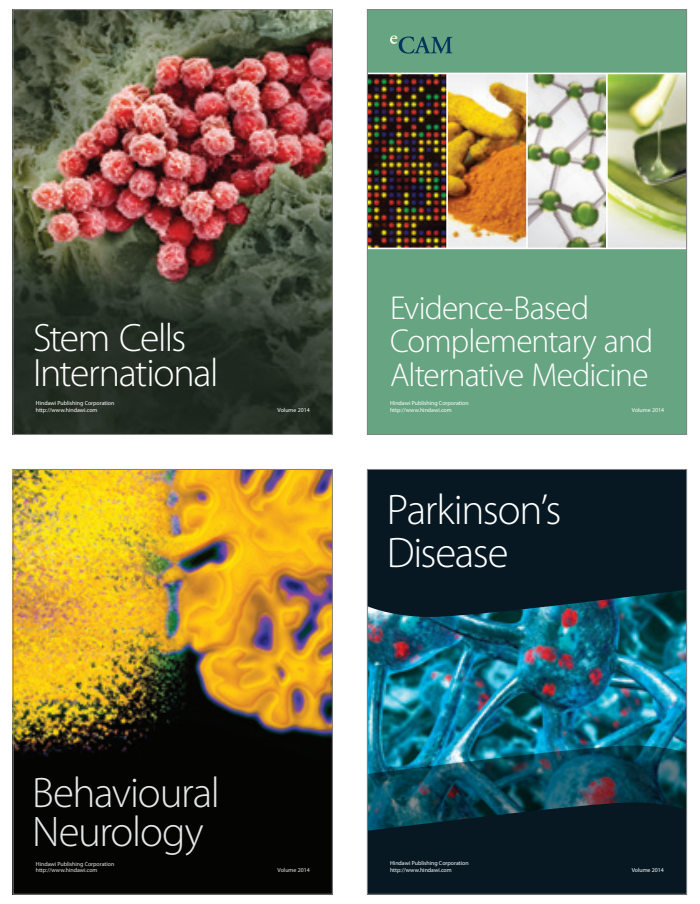
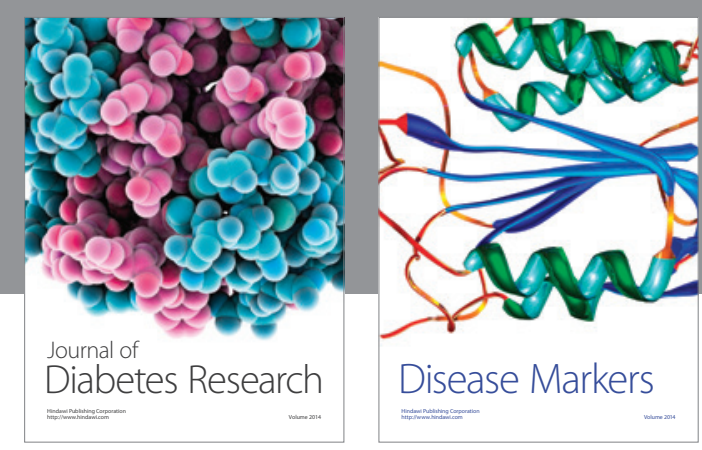

Disease Markers
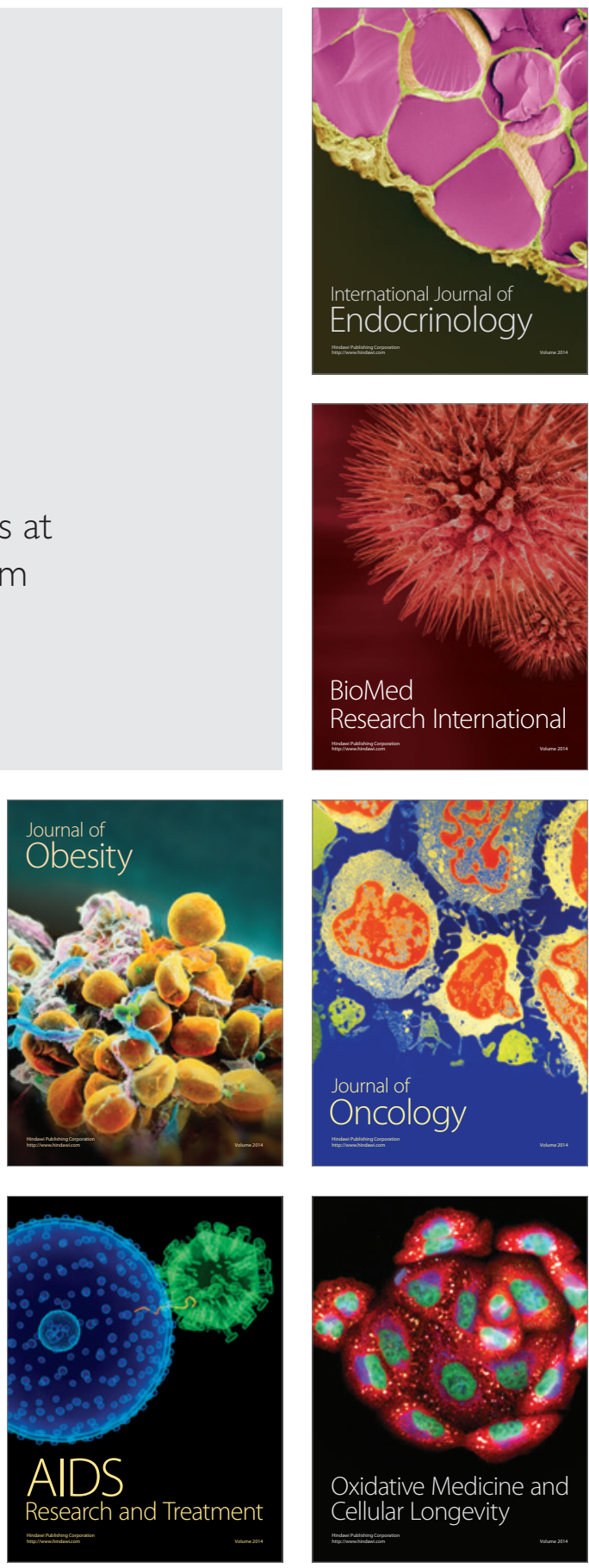